\title{
Bond Strength to Primary Teeth Dentin Following Disinfection with 2\% Chlorhexidine
}

\section{Faika Y Abdelmegid*}

Department of Oral Medicine and Diagnostic Sciences, College of Dentistry, King Saud University, Kingdom of Saudi Arabia

*Corresponding author: Associate Prof. Faika Y Abdelmegid, BDS, MS, Department of Oral Medicine and Diagnostic Sciences, College of Dentistry, King Saud University, PO BOX: 60169, Riyadh, Kingdom of Saudi Arabia, E-mail: famegid@ hotmail.com; fabdelmegid@ksu.edu.sa

\begin{abstract}
Objectives: To assess the influence of $2 \%$ chlorhexidine gluconate applied for 20 or 40 seconds on the Shear Bond Strength (SBS) of a nanohybrid resin-composite Filtek Z350XT with Single Bond Universal Adhesive and Photac Fil resin-modified glass-ionomer with Ketac conditioner to Caries Affected Dentin (CAD) of primary teeth.

Methods: Seventy-two specimens of CAD primary dentin were randomly divided into 6 groups, 12 each according to the materials and application of $2 \%$ chlorhexidine (no application or application for 20 or 40 seconds). Restorative materials were applied using a standard PVC tube. SBS was measured using an Instron machine running at a crosshead speed of $0.5 \mathrm{~mm} / \mathrm{min}$. The modes of failures/fractures were verified using stereomicroscope.
\end{abstract}

Results: Mean ( \pm SD) SBS in MPa of Filtek Z350XT and Photac Fil with no application of chlorhexidine or after application of chlorhexidine for 20 or 40 seconds were $14.13 \pm$ $2.09,16.45 \pm 2.41$, and $15.91 \pm 3.11,12.56 \pm 2.44,14.10 \pm$ 3.10 and $13.83 \pm 3.11$, respectively. Regardless of the surface treatment, Filtek Z350XT showed significantly greater SBS than Photac Fil $(p=0.01)$. The effect of surface treatment on SBS was not statistically significantly different $(p$ $=0.06$ ) from one another for each tested material. Stereoscopic examination of the debonded samples of all groups of Filtek Z350XT exhibited mostly cohesive fracture of the material while for Photac Fil exhibited mostly adhesive fracture. Failure mode analysis revealed significant differences $(p<0.0001)$ between Filtek Z350XT and Photac Fil.

Conclusions: The nanohybrid resin-composite Filtek Z350XT with Single Bond Universal Adhesive demonstrated higher shear bond strength than Photac Fil resin-modified glass-ionomer with Ketac conditioner to CAD dentin of primary teeth. The $2 \%$ chlorhexidine gluconate applied for 20 or 40 seconds before acid etching or conditioning of the CAD dentin did not affect SBS of the two materials. The mode of failure of Filtek
Z350XT exhibited mostly cohesive fracture of the material while for Photac Fil exhibited mostly adhesive fracture.

\section{Keywords}

Chlorhexidine gluconate, Primary teeth, Shear bond strength, Dentin disinfection

\section{Introduction}

In clinical practice, the most frequent tooth substrate that dentists restore is demineralized dentin or Caries-Affected Dentin (CAD) [1]. Therefore, it is important to understand the CAD's physical properties and mechanism of adhesion for the advancement of conservative restorative dentistry. Exploration of interfaces between the adhesive in sound and carious dentin may increase our appreciation on how bonding to dentin is affected by the properties of dentin in primary teeth. The bond of sound dentin to the adhesive is stronger than with CAD [2] and hence, the reduced bond strength leads to failure of the restoration over time. This problem remains unresolved and has raised interest in studies of the strength of the bond between the sound or $C A D$ and restorative materials.

Carious dentin consists of two layers, the inner less infected, demineralized with possible repairing layer and the outer necrotic, highly infected layer [3]. Clinical$l y$, after removing caries where the restorative material is bonded, CAD is frequently encountered [4]. Clinically, dentists are frequently working with caries infected dentin, sclerotic, CAD [4]. The chemical and physical characteristics of CAD are different from those of sound dentin [5]. Partial demineralization of CAD makes it soft-

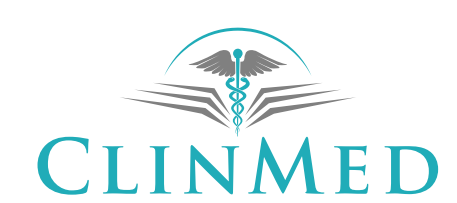

INTERNATIONAL LIBRARY
Citation: Abdelmegid FY (2018) Bond Strength to Primary Teeth Dentin Following Disinfection with 2\% Chlorhexidine. Int J Oral Dent Health 4:049. doi.org/10.23937/2469-5734/1510049 Received: November 24, 2017: Accepted: December 19, 2017: Published: January 15, 2018 Copyright: (c) 2018 Abdelmegid FY. This is an open-access article distributed under the terms of the Creative Commons Attribution License, which permits unrestricted use, distribution, and reproduction in any medium, provided the original author and source are credited. 
Table 1: Descriptive statistics of the SBS in MPa to dentin of primary molars $(n=12)$.

\begin{tabular}{|c|c|c|c|c|c|c|c|}
\hline Group \# & Material & Adhesive & Surface Treatment & Mean & Std Dev & Minimum & Maximum \\
\hline 1 & Filtek Z350XT & $\begin{array}{l}\text { Single Bond } \\
\text { total-etch }\end{array}$ & No treatment (Control) & 14.13 & 2.09 & 7.63 & 13.94 \\
\hline 2 & Filtek Z350XT & $\begin{array}{l}\text { Single Bond } \\
\text { total-etch }\end{array}$ & $\begin{array}{l}\text { chlorhexidine for } 20 \\
\text { seconds }\end{array}$ & 16.45 & 2.41 & 9.35 & 17.47 \\
\hline 3 & Filtek Z350XT & $\begin{array}{l}\text { Single Bond } \\
\text { total-etch }\end{array}$ & $\begin{array}{l}\text { chlorhexidine for } 40 \\
\text { seconds }\end{array}$ & 15.91 & 3.11 & 9.48 & 18.48 \\
\hline 4 & Photac Fil & $\begin{array}{l}\text { Ketac }^{\mathrm{TM}} \\
\text { conditioner }\end{array}$ & No treatment (Control) & 12.56 & 2.44 & 6.24 & 12.91 \\
\hline 5 & Photac Fil & $\begin{array}{l}\text { Ketac }^{\mathrm{TM}} \\
\text { conditioner }^{-}\end{array}$ & $\begin{array}{l}\text { chlorhexidine for } 20 \\
\text { seconds }\end{array}$ & 14.10 & 3.10 & 5.93 & 14.97 \\
\hline 6 & Photac Fil & $\begin{array}{l}\text { Ketac }^{\mathrm{TM}} \\
\text { conditioner }\end{array}$ & $\begin{array}{l}\text { chlorhexidine for } 40 \\
\text { seconds }\end{array}$ & 13.83 & 3.11 & 5.97 & 15.47 \\
\hline
\end{tabular}

er and more porous than sound dentin, with a thick hybrid layer compared to sound dentin [6,7]. Bonding to CAD and sound dentin depend on the adhesive systems used and the type of dentin [8].

With minimal intervention techniques, however, there is greater risk of leaving more residual bacteria in the cavity after caries removal, which can result in secondary caries [9]. For this reason, disinfectant solutions have been introduced as alternative means to decrease or eradicate bacteria during preparations of cavities that may contribute to secondary caries and restoration failure [10]. Chlorhexidine is commonly used broad-spectrum antiseptic or antibacterial materials in dentistry. It has demonstrated to be very effective in the maintenance of plaque control and gingivitis in both short- and long-term in vivo studies without developing resistant organisms [11,12]. Chlorhexidine solutions have been also suggested to be placed after cavity preparation to disinfect dentin [10]. A study evaluated the effect of using $2 \%$ chlorhexidine to primary dentin for 30 seconds following application of phosphoric acid concluded that its application at low concentrations increase bond strength over time and prevent hybrid layer degradation [13]. The results of in vitro investigations are debatable regarding the disinfectant's effect on adhesion $[10,14,15]$. Because of the conflicting results reported in the above studies regarding bonding to CAD and minimal information about bonding the new restorative materials to CAD of primary teeth after using disinfectant solutions. Hence, the purposes of this in vitro study were to determine the SBS of a nanohybrid resin-composite Filtek Z350XT with Single Bond Universal Adhesive and Photac Fil resin-modified glass-ionomer with Ketac conditioner to CAD of primary teeth after using chlorhexidine as cavity disinfectant for 20 or $\mathbf{4 0}$ seconds and determine failure mode of fractured surfaces using stereomicroscope. The null hypothesis was there is no difference in the effect of the application of chlorhexidine cavity disinfectant for 20 or 40 seconds on the SBS of the two tested restorative materials to CAD of primary teeth.

\section{Materials and Methods}

\section{Preparation of specimens}

Seventy-two extracted primary molars with mild to moderate caries were stored in $0.1 \%$ thymol to use in this investigation. Caries removal with round carbide burs (SS WHITE, New Jersey, USA) in a slow-speed handpiece was completed leaving CAD using the properties of visual inspection and degree of hardness to a sharp excavator [8]. Teeth were then prepared with the occlusal surfaces exposed and mounted inside a tube-shaped plastic rings, $3 \mathrm{~cm} \times 3 \mathrm{~cm}$ using self-polymerizing acrylic resin (Ortho-Jet, Lang Dental MFG.Co., Inc., IL, USA). Then, the occlusal surfaces were polished with 240, 320, 400, and 600 silicon carbide paper (JEANWIRTZ GmbH \& Co. Charlottestrabe Dusseldorf W. Germany) under running water to produce a uniform surface and similar smear layer. Specimens were randomly allocated into 6/groups of 12/each (Table 1) and kept for 24 hours in distilled water. Two examiners assessed CAD which was left on the dentin surface. For the inter-examiner reliability in evaluating the type of dentin, Kappa was 0.90, which shows very good agreement.

\section{Bonding procedures}

Consepsis (Ultradent Products, Inc. South Jordan, UT, USA), a $2 \%$ chlorhexidine gluconate was applied to the experimental groups using a disposable brush tip and left undisturbed for 20 or 40 seconds, rinsed with water for 20 seconds and dried with absorbent paper. A nanohybrid resin-composite Filtek Z350XT with Single Bond Universal Adhesive (3M ESPE St. Paul, MN, USA) and Photac Fil Quick Aplicap resin-modified glass-ionomer with Ketac conditioner (3M ESPE) were used in this investigation. The dentin surface was treated according to the instructions of the manufacturer of each material and lightcured (Elipar S10 LED Curing Light - 3M ESPE) according to the manufacturer's instructions. Restorative materials were applied using a standard PVC tube with a height of 2-mm and internal diameter of 2-mm which was positioned perpendicular to the dentin and each material was carefully inserted into the tube and cured according to the instructions of the manufacturer. All groups were stored for 72 hours in distilled water at room temperature $\left(24^{\circ} \mathrm{C}\right)$ prior to thermocycling for 1,000 cycles between $5^{\circ}$ and $55^{\circ} \mathrm{C}$ with a 20 -sec dwell time and transfer time of $10 \mathrm{~s}$ based on the standards of the International Organization for Standardization $[16,17]$. 
Table 2: Frequency and percentage of bond failure type.

\begin{tabular}{|l|l|l|l|l|l|l|}
\hline Group \# & \multicolumn{2}{|l|}{ Cohesive Fracture of the Material } & \multicolumn{2}{|c|}{ Adhesive Fracture } & \multicolumn{2}{l|}{ Cohesive Fracture of Dentin } \\
\hline & N & $\%$ & N & $\%$ & N & \% \\
\hline 1 & 8 & 66.67 & 3 & 25 & 1 & 8.33 \\
\hline 2 & 8 & 66.67 & 2 & 16.67 & 2 & 16.67 \\
\hline 3 & 9 & 75 & 2 & 16.67 & 1 & 8.33 \\
\hline 4 & 4 & 33.33 & 7 & 58.33 & 1 & 8.33 \\
\hline 5 & 3 & 25 & 8 & 66.67 & 1 & 8.33 \\
\hline 6 & 4 & 33.33 & 7 & 58.33 & 1 & 8.33 \\
\hline
\end{tabular}

\section{Bond strength test}

SBS was determined using a universal testing machine (Instron, model no. 8500, Canton, MA, USA) at 0.5 $\mathrm{mm} / \mathrm{minute}$ crosshead speed and expressed in MPa.

\section{Evaluation of failure mode}

Two investigators evaluated fractured surfaces under a stereomicroscope (Nikon Model C-DSD230, Nikon Co. Tokyo, Japan) with digital camera (DXM1200F Nikon Co. Tokyo, Japan) at X25 magnification. Failures were classified as adhesive fracture interface $(100 \%$ of the bonded interface failed between dentin and adhesive bonding), cohesive fracture of the material (100\% of failure in the material), and cohesive fracture of dentin (100\% of failure in the dentin). For the inter-examiner reliability in evaluating the three types of failures, Kappa was 0.83 showing very good agreement between the two examiners.

\section{Statistical analysis}

Descriptive statistics and one-way ANOVA and Tukey HSD test were applied to compare SBS across different groups. A $(p<0.05)$ was used as a level for statistical significance. Cohen's kappa statistics was determined to compute agreement between the two examiners in evaluating dentin and failure types. Software Package Statistical Analysis (SPSS) statistical software version 16 (SPSS Inc., Chicago, IL, USA) was used.

\section{Results}

The outcomes of the SBS expressed in MPa and the descriptive statistics are presented in Table 1. Mean ( \pm SD) SBS in MPa of Filtek Z350XT with no application of chlorhexidine or after application of chlorhexidine for 20 or 40 seconds were $14.13 \pm 2.09,16.45 \pm 2.41$, and $15.91 \pm 3.11$, respectively. While the mean SBS of Photac Fil with no application of chlorhexidine or after application of chlorhexidine for 20 or 40 seconds were $12.56 \pm$ $2.44,14.10 \pm 3.10$ and $13.83 \pm 3.11$, respectively.

An ANOVA model was used to analyze the data. Factors initially included were type of material, type of surface treatment, and their interaction. The interaction was found to be not significant, so it was removed, leaving a main effect only model. The ANOVA indicated that there was statistically significant difference between the two materials. Regardless of the surface treatment, Filtek Z350XT showed significantly greater SBS than
Photac Fil ( $p=0.01)$. The effect of surface treatment on SBS was not statistically significantly different $(p=0.06)$ from one another for each tested material.

Table 2 shows the results of the types of fractures observed. Stereoscopic examination of the debonded samples of all groups of Filtek Z350XT exhibited mostly cohesive fracture of the material while for Photac Fil exhibited mostly adhesive fracture. Failure mode analysis revealed significant differences $(p<0.0001)$ between Filtek Z350XT and Photac Fil.

\section{Discussion}

The null hypothesis of this study was partially rejected, as there was a difference in the bond strength of the two tested materials after the application of chlorhexidine cavity disinfectant but not the application time to CAD of primary teeth. The nanohybrid resin-composite Filtek Z350XT with Single Bond Universal Adhesive demonstrated higher shear bond strength than Photac Fil light-curing glass-ionomer with Ketac conditioner to CAD of primary teeth. Another investigation indicated no significant difference in bond strength with the selfetch adhesive to CAD compared to sound dentin of primary teeth and significantly higher bond strength when the conventional adhesive was used [18].

Investigation using different adhesives and restorative materials reported bond strength ranging from 6.2 to $18.2 \mathrm{MPa}$ to dentin of primary teeth [19-21]. The reported numbers are similar with the results of this study for both tested restorative materials. Variations in bond strength can reflect many factors including adhesive and bond strength used, the quality and location of dentin, and the specimen storage medium [8,22,23]. Investigation of resin-modified glass-ionomer bonded to carious and sound primary dentin showed greater SBS when pretreated with polyacrylic acid, except for Vitrebond on sound dentin [24]. Lesser bond strengths and adhesive fracture were found for Photac Fil in the present study, indicating that SBS may represent the strength of adhesive bonding by itself. Another factor to consider is the bond strength of adhesives to dentin is the calcium content, which reduced when dentin is closer to the pulp, resulting in lesser bond strengths [19]. In the present study, the dentin was ground to a uniform surface and location. However, despite the effort to have the bonded surface at the same distance from the pulp, that may not be might possible and the 
surfaces represent different distances from the pulp. In addition, bond strength in deep dentin has higher moisture content and less intertubular material [22]. Similarly, the bond strength of dentin may be inconsistent due to different organic and water content [24].

Adhesives share main part in stabilizing the hybrid layer as well as creating extension tags into the dentinal tubules [25]. The mechanism of bonding is established on the effect of hybridization and formation of resin tags $[26,27]$. The ethanol and water in Single Bond may assist in penetration of resin into the collagen structure [28]. Compared to permanent teeth, smear layers are easier to remove from primary, which may suggest greater reactivity to the acidic conditioners used on dentin [29]. A study reported that $2 \%$ chlorhexidine reduce SBS of Single Bond to dentin than the etch gel with chlorhexidine and the acid etch alone [30]. A study concluded that after etching the dentin, the use of $2 \%$ chlorhexidine and $1 \%$ benzalkonium chloride solutions, as cavity disinfectants did not influence the tensile and SBS of One Step and Optibond Solo [31]. Another study indicated significant lower bond strength to sound and CAD of primary teeth compared with permanent teeth [32]. A study concluded that CAD bond strength and nanoleakage in primary teeth are negatively affected after using different adhesive systems [33]. In this investigation, the mode of failure of Filtek Z350XT exhibited mostly cohesive fracture of the material while Photac Fil exhibited mostly adhesive fracture. A previous study reported adhesive failures were more frequently seen in primary dentin [34]. Another study concluded that use of chlorhexidine interferes with the SBS of resin-modified glass-ionomer cement to dentin [35]. Another study using resin-composite reported that cavity disinfectants might be material specific regarding their interactions with different dentin bonding materials [10]. More studies found that chlorhexidine application before and after acid etching did not significantly influenced the dentin bonding system [36-38]. However, another study indicated that application of the chlorhexidine before and after acid etching significantly decreased the SBS to dentin [14]. The outcomes of this in vitro investigation showed that the mean SBS was less than $17.6 \mathrm{Mpa}$, which considered the minimum value recommended for bond strength to dentin in primary and permanent teeth [39]. A recent study showed the association between the concentration of chlorhexidine and the bond strength is not linear [40].

The results of this investigation should consider the limitations including the restricted number of restorative materials used. Diverse and additional materials are beneficial to test. In addition, the study did not test application of chlorhexidine on the SBS immediately, after shorter application time, and for aged specimens. However, even with these limitations, the study indicated encouraging results of the in vitro values, which may have clinical implications. Another limitation is it is in vitro setting and the clinical condition in the mouth is not easy to mimic in the laboratory [41]. However, in this in vitro study, standardization of experimental conditions was advantage and the results demonstrated a clear correlation between SBS of the two tested materials to CAD of primary teeth.

\section{Conclusions}

Under the experimental conditions of this in vitro investigation, the results of this study concluded that:

1. The nanohybrid resin-composite Filtek Z350XT with Single Bond Universal Adhesive demonstrated higher shear bond strength than Photac Fil resin-modified glass-ionomer with Ketac conditioner to CAD of primary teeth.

2. The $2 \%$ chlorhexidine gluconate applied for 20 or 40 seconds before acid etching or conditioning of the $C A D$ did not influence shear bond strength of Filtek Z350XT and Photac Fil.

3. The mode of failure of Filtek Z350XT was mostly cohesive fracture of the material while Photac Fil exhibited mostly adhesive fracture.

\section{Acknowledgment}

The authors wish to thank College of Dentistry Research Center and Deanship of Scientific Research at King Saud University, Saudi Arabia for funding this research. In addition, the author wishes to express sincere thanks to Mr. Nassr Al Maflehi for his valuable help in the statistical analysis.

\section{References}

1. Perdigao J (2010) Dentin bonding-variables related to the clinical situation and the substrate treatment. Dent Mater 26: e24-e37.

2. Erhardt MC, Toledano M, Osorio R, Pimenta LA (2008) Histomorphologic characterization and bond strength evaluation of caries-affected dentin/resin interfaces: effects of long-term water exposure. Dent Mater 24: 786-798.

3. Fusayama T (1979) Two layers of carious dentin; diagnosis and treatment. Oper Dent 4: 63-70.

4. Harnirattisai C, Inokoshi S, Shimada Y, Hosoda H (1992) Interfacial morphology of an adhesive composite resin and etched caries-affected dentin. Oper Dent 17: 222-228.

5. Nakajima M, Kitasako Y, Okuda M, Foxton RM, Tagami J (2005) Elemental distributions and microtensile bond strength of the adhesive interface to normal and caries affected dentin. J Biomed Mater Res B Appl Biomater 72: 268-275.

6. Pashley DH, Carvalho RM (1997) Dentine permeability and dentine adhesion. J Dent 25: 355-372.

7. Swift EJ Jr (2002) Dentin/enamel adhesives: review of the literature. Pediatr Dent 24: 456-461.

8. Nakajima M, Sano H, Burrow MF, Tagami J, Yoshiyama M, et al. (1995) Tensile bond strength and SEM evaluation of caries-affected dentin using dentin adhesives. J Dent Res 74: 1679-1688. 
9. Weerheijm KL, Groen HJ (1999) The residual caries dilemma. Community Dent Oral Epidemiol 27: 436-441.

10. Meiers JC, Kresin JC (1996) Cavity disinfectants and dentin bonding. Oper Dent 21: 153-159.

11. Osso D, Kanani N (2013) Antiseptic mouth rinses: An update on comparative effectiveness, risks and recommendations. J Dent Hyg 87: 10-18.

12. Brightman RG, Terezhalmy GT, Greenwell $H$, Jacobs $M$, Enlow DH (1991) The effects of 0.12 percent chlorhexidine gluconate mouthrinse on orthodontic patients ages 11 through 17 with established gingivitis. Am J Orthod Dentofacial Orthop 100: 324-329.

13. Leitune VC, Portella FF, Bohn PV, Collares FM, Samuel SM (2011) Influence of chlorhexidine application on longitudinal adhesive bond strength in deciduous teeth. Braz Oral Res 25: 388-392.

14. Gürgan S, Bolay S, Kiremitçi A (1999) Effect of disinfectant application methods on the bond strength of composite to dentin. J Oral Rehabil 26: 836-840.

15. Ozturk B, Ozer F (2004) Effect of $\mathrm{NaOCl}$ on bond strengths of bonding agents to pulp chamber lateral walls. J Endod 30: 362-365.

16. Ricci HA, Scheffel DL, Mariusso MR, Spolidorio DM, de Souza Costa CA, et al. (2014) Exposed collagen in resin bonds to caries-affected dentin after dentin treatment with aqueous and alcoholic chlorhexidine solutions. J Adhes Dent 16: 21-28.

17. International Organization for Standardization (1994) ISO/ TR 11405. Dental material - Guidance on testing of adhesion to tooth structure.

18. Nakornchai S, Harnirattisai C, Surarit R, Thiradilok S (2005) Microtensile bond strength of a total-etching versus self-etching adhesive to caries-affected and intact dentin in primary teeth. J Am Dent Assoc 136: 477-483.

19. Bordin-Aykroyd S, Sefton J, Davies EH (1992) In vitro bond strengths of three current dentin adhesives to primary and permanent teeth. Dent Mater 8: 74-78.

20. Hosoya Y, Kawashita Y, Yoshida M, Suefuji C, Marshall GW Jr (2000) Fluoridated light-activated bonding resin adhesion to enamel and dentin: Primary vs permanent. Pediatr Dent 22: 101-106.

21. Burrow MF, Nopnakeepong U, Phrukkanon S (2002) A comparison of microtensile bond strengths of several dentin bonding systems to primary and permanent dentin. Dent Mater 18: 239-245.

22. Yoshiyama M, Carvalho R, Sano H, Horner J, Brewer PD, et al. (1995) Interfacial morphology and strength of bonds made to superficial versus deep dentin. Am J Dent 8: 297-302.

23. Oilo G, Olsson S (1990) Tensile bond strength of dentin adhesives: A comparison of materials and methods. Dent Mater 6: 138-144.

24. Way JL, Caputo AA, Jedrychowski JR (1996) Bond strength of light-cured glass ionomers to carious primary dentin. ASDC J Dent Child 63: 261-264.

25. Meerbeek BW, Inoue S, Perdigao J, Lambrechts $P$, Vanherle G (2001) Enamel and dentin adhesion. In: Summitt JB, Robbin JW, Schwartz RS, Fundamentals of Operative Dentistry. ( $2^{\text {nd }}$ edn), Quintessence Publishing, Singapore, 178-235.

26. Eick JD, Robinson SJ, Byerley TJ, Chappelow CC (1993) Adhesives and nonshrinking dental resins of the future. Quintessence Int 24: 632-640.
27. Van Meerbeek B, Dhem A, Goret-Nicaise $M$, Braem $M$, Lambrechts P, et al. (1993) Comparative SEM and TEM examination of the ultrastructure of the resin-dentin interdiffusion zone. J Dent Res 72: 495-501.

28. Nunes MF, Swift EJ, Perdigão J (2001) Effects of adhesive composition on microtensile bond strength to human dentin. Am J Dent 14: 340-343.

29. Nör JE, Feigal RJ, Dennison JB, Edwards CA (1996) Dentin bonding: SEM comparison of the resin-dentin interface in primary and permanent teeth. J Dent Res 75: 1396-1403.

30. Vieira Rde S, da Silva A Jr (2003) Bond strength to primary tooth dentin following disinfection with a chlorhexidine solution: an in vitro study. Pediatr Dent 25: 49-52.

31. Say EC, Koray F, Tarim B, Soyman M, Gülmez T (2004) In vitro effect of cavity disinfectants on the bond strength of dentin bonding systems. Quintessence Int 35: 56-60.

32. Lenzi TL, Tedesco TK, Soares FZ, Loguercio AD, Rocha Rde O (2012) Chlorhexidine does not increase immediate bond strength of etch-and-rinse adhesive to caries-affected dentin of primary and permanent teeth. Braz Dent J 23: 438-442.

33. Alves FB, Lenzi TL, Reis A, Loguercio AD, Carvalho TS, et al. (2013) Bonding of simplified adhesive systems to caries-affected dentin of primary teeth. J Adhes Dent 15: 439-445.

34. Can-Karabulut DC, Oz FT, Karabulut B, Batmaz I, Ilk O (2009) Adhesion to primary and permanent dentin and a simple model approach. Eur J Dent 3: 32-41.

35. Sekhar A, Anil A, Thomas MS, Ginjupalli K (2017) Effect of various dentin disinfection protocols on the bond strength of resin modified glassionomer restorative material. J Clin Exp Dent 9: e837-e841.

36. de Castro FL, de Andrade MF, Duarte Júnior SL, Vaz LG, Ahid FJ (2003) Effect of $2 \%$ chlorhexidine on microtensile bond strength of composite to dentin. J Adhes Dent 5: 129-138.

37. El-Housseiny AA, Jamjoum H (2000) The effect of caries detector dyes and a cavity cleansing agent on composite resin bonding to enamel and dentin. $\mathrm{J}$ Clin Pediatr Dent 25: 57-63.

38. de Souza-Filho FJ, Soares Ade J, Vianna ME, Zaia AA, Ferraz CC, et al. (2008) Antimicrobial effect and pH of chlorhexidine gel and calcium hydroxide alone and associated with other materials. Braz Dent J 19: 28-33.

39. el Kalla IH, García-Godoy F (1998) Bond strength and interfacial micromorphology of four adhesive systems in primary and permanent molars. ASDC J Dent Child 65: 169-176.

40. Collares FM, Rodrigues SB, Leitune VC, Celeste RK, Borba de Araújo F, et al. (2013) Chlorhexidine application in adhesive procedures: a meta-regression analysis. J Adhes Dent 15: 11-18.

41. Eliades T, Bourauel C (2005) Intraoral aging of orthodontic materials: the picture we miss and its clinical relevance. Am J Orthod Dentofacial Orthop 127: 403-412. 